\title{
Vanadium Intoxication Inhibits Sulfhydryl Groups and Glutathione in the Rat Brain
}

\author{
Key words: Vanadium - Rat brain - Neurotoxicity - Sulf hydryl groups - \\ Glutathione
}

The human health hazards following exposure to the combustion products of vanadium-bearing oils, fumes and dusts in metallurgical operations have stimulated great interest in vanadium toxicology. Impairments of the central nervous system have been demonstrated in the vanadium exposed animals. ${ }^{1)}$ To date, the mechanisms of these effects are incompletely defined. Several researchers have reported that glutathione and sulfhydryl groups play a protective role against free radical mediated or peroxidative damage. ${ }^{2,3}$ It is well known that enzymes possessing an essential sulfhydryl group are non-competitively inhibited by heavy metal ions. Our earlier investigations have revealed depletion of sulfhydryl groups in the rat brain, treated with heavy metals, thallium and trimethyltin.,5) This study determines if the neurotoxicity of vanadium would be reflected in significant alterations in the concentration of sulfhydryl groups in the different regions of the rat brain.

Sixteen adult male albino rats $(150-200 \mathrm{~g})$ were used in all experiments. Food (Hindustan Lever Laboratory Feeds, India) and water were freely available in the cages throughout the experiment. Two batches of eight rats each were divided 4 per cage. Group 1 served as physiological saline controls and group 2 received intraperitoneal injections of sodium metavanadate solution $(5 \mathrm{mg} / \mathrm{kg}$ body wt) for 5 days. Rats were fasted overnight and sacrificed by decapitation. Brains were dissected into various regions viz: cerebral hemisphere, cerebellum, and the brain stem on an ice plate and weighed to the nearest milligram. Various parts of the brain were homogenized with a teflon pestle in chilled $0.15 \mathrm{M} \mathrm{KCl}$, volume was adjusted to give a $10 \% \mathrm{w} / \mathrm{v}$ homogenate. Glutathione or free sulfhydryl groups (Non-protein bound), and total sulfhydryl groups (protein bound) were determined according to the procedure of Sedlak and Lindsay (1968). ${ }^{6)}$

Neurological signs such as muscular fasciculations, asphyxiation, lethargy and severe ataxia followed by diarrhoea were observed. The data embodied in Tables 1 and 2 depict significant lowering of the levels of total sulfhydryl groups and glutathione in the different regions of the rat brain following vanadium intoxication. A significant decrement in the concentration of total sulfhydryl groups was observed in the cerebrum $(-32 \%, \mathrm{P}<0.05)$ and the brain stem $(-48 \%, \mathrm{P}<0.02)$. Interestingly, glutathione was remarkably diminished in the cerebrum $(-82 \%, \mathrm{P}<0.001)$, cerebellum $(-78 \%, \mathrm{P}<0.001)$ and in the brain stem $(-83 \%, \mathrm{P}<0.001)$.

Effects of vanadium intoxication on the contents of sulfhydryl groups and glutathione is an unexplored area of neurochemical research. However, we have demonstrated inhibition of sulfhydryl groups in the rat brain after thallium and 
Table 1. Levels of total sulfhydryl groups in the different regions of rat brain following Vanadium toxicity

\begin{tabular}{lccc}
\hline \multirow{2}{*}{ Brain regions } & \multicolumn{3}{c}{ Micro moles SH/g tissue } \\
\cline { 2 - 4 } & Control & Vanadium & $\%$ change \\
\hline Cerebrum & $11.072 \pm 0.304$ & $7.50 \pm 0.649^{*}$ & -32 \\
Cerebellum & $10.572 \pm 0.344$ & $8.593 \pm 0.520$ & -19 \\
Brain stem & $11.852 \pm 0.372$ & $6.126 \pm 0.631^{* *}$ & -48 \\
\hline
\end{tabular}

Each value represents \pm standard error of six animals.

Vanadium ( $5 \mathrm{mg} / \mathrm{kg}$ body $\mathrm{wt}$.) was administered intraperitoneally daily for 5 days.

$\mathrm{P}$ values: $*<0.05 ; * *<0.02$

Table 2. Effects of vanadium on the glutathione contents in the different regions of the rat brain

\begin{tabular}{lccc}
\hline \multirow{2}{*}{ Brain regions } & \multicolumn{3}{c}{ Micro moles SH/g tissue } \\
\cline { 2 - 4 } & Control & Vanadium & $\%$ change \\
\hline Cerebrum & $2.126 \pm 0.081$ & $0.376 \pm 0.134^{* * *}$ & -82 \\
Cerebellum & $2.037 \pm 0.108$ & $0.440 \pm 0.060^{* * *}$ & -78 \\
Brain stem & $1.693 \pm 0.093$ & $0.295 \pm 0.040 * * *$ & -83 \\
\hline
\end{tabular}

Each value represents \pm standard error of six animals.

Vanadium ( $5 \mathrm{mg} / \mathrm{kg}$ body $\mathrm{wt}$.) was administered intraperitoneally daily for 5 days.

$\mathrm{P}$ value : *** $<0.001$

trimethyltin administration. ${ }^{4,5,7)}$ Only few reports in the literature showed that vanadium exposure to the animals decreased serum protein sulfhydryl radicals. ${ }^{1)}$ Findings of this investigation revealed lowering of sulfhydryl groups and glutathione in the rat brain. The results of this study are well in concordance with previous reports, exhibiting decrement of sulfhydryl groups in the rat brain. ${ }^{\text {) }}$ Two possible explanations can be given to discuss our findings. Firstly, prefential binding of vanadium to the sulfhydryl groups might have catabolyzed sulfhydryl amino acids and led to their decrement in the rat brain. Secondly, vanadium intoxication possibly decreased sulfhydryl groups by lowering the activity of enzyme succinic dehydrogenase.

\section{ACKNOWLEDGMENTS}

Senior Author (SSH) was a Senior Research Officer of the Indian Council of Medical Research at the National Institute of Occupational Health, Ahmedabad, India. The authors thank Mr. Edgar Calago for typing this manuscript. 


\section{REFERENCES}

1) Waters MD. Toxicology of Vanadium. In: Goyer RA, Mehlman eds. Toxicology of Trace Elements. Vol. II, Washington DC: Hemisphere Publishing Corp., 1967; 147-85.

2) Delucia AJ, Haque PM, Mustafa MG, Cross CE. Ozone interaction with rat lung. I. Effect on sulfhydryl radicals and sulfhydryl-containing enzyme activities. J Lab Clin Med 1972; 80: 559-66.

3) Chow CK, Tappel AL. An enzymatic protective mechanism against lipid peroxidation damage to lungs of ozone exposed rats. Lipids 1972; 7: 518-24.

4) Hasan M, Ali SF. Effect of thallium, nickel and cobalt administration on the lipid peroxidation in different regions of rat brain. Toxicol Appl Pharmacol 1981; 57: 8-13.

5) Hasan M, Haider SS, Bajpai VK. The biochemical and Ultrastructural studies on the effects of trimethyltin on regional brain lipid profiles and lipid peroxidation. Ind Health 1984; 22: 107-16.

6) Sedlak JI, Lindsay RH. Estimation of total protein-bound, and non-protein bound sulfhydryl groups in tissue with Ellman's reagent. Anal Biochem 1968; 25: 192-205.

7) Yoshino Y, Mozai T, Nakako K. Biochemical changes in the brain of rats poisoned with an alkylmercury compound, with special reference to the inhibition of protein synthesis in brain cortex slice. J Neurochem 1966; 13: 1223-30.

National Institute of Occupational Health,

Ahmedabad-380016

1) Present Address:

Department of Biochemistry Faculty of Medicine

Al-Arab Medical University Benghazi, Libya (S.P.L.A.J)

Address for Correspondence:

Post Box 15257, Al-Kish Benghazi, Libiya (S.P.L.A.J.)
Syed Saleem :HAIDER ${ }^{1)}$ and

S.K. KASHYAP

(Received August 6, 1988 and in revised form December 7, 1988) 